\title{
A genetic investigation of enzyme polymorphisms shared by wolf and dog: suggestions for conservation of the wolf in Italy
}

\author{
Rita LORENZINI and Rosario FICO
}

\begin{abstract}
Lorenzini R. and Fico R. 1995. A genetic investigation of enzyme polymorphisms shared by wolf and dog: suggestions for conservation of the wolf in Italy. [In: Ecological genetics in mammals II. G. B. Hartl and J. Markowski, eds]. Acta Theriologica, Suppl.
\end{abstract} 3: $101-110$.

In order to provide suggestions for conservation and management of the wolf Canis lupus Linnaeus, 1758 in Italy, a total of 46 wolves from central Italy and 53 mongrel dogs were surveyed for electrophoretic variation within and among populations. Six out of 41 presumptive gene loci exhibited polymorphism in the wolf $(P=$ proportion of polymorphic loci $=0.146,99$ per cent criterion), whilst only 3 loci were variable in the $\operatorname{dog}(P=0.073)$. Expected average heterozygosity in the Italian wolf (mean $H_{e}=$ 0.037 ) was comparable to values reported previously for protein variation in natural wolf populations. By contrast, the dog showed a comparatively low heterozygosity (mean $H_{e}=0.020$ ), which may be a consequence of domestication. Nei's (1978) absolute genetic distance between wolf and $\operatorname{dog}(D=0.012)$ was very similar to values reported in previous investigations, thus confirming that they are closely related forms. Relative genetic differentiation (Wright's $F_{S T}=0.167$ ) between wolf and dog was considerably higher than the mean genetic diversity found among several dog breeds. The sesults of the present genetic investigation on the wolf population from central Italy suggested that its genetic resources are quite intact. The extent of differences in allelic frequencies at loci polymorphic both in wolf and dog did not suggest substantial wolf-dog interbreeding, which has been thought to be one of the major threats to the genetic integrity of the Italian wolf population.

Istituto Zooprofilattico Sperimentale dell'Abruzzo e del Molise "G. Caporale", Campo Boario, 64100, Teramo, Italy

Key words: Canis lupus, dog, protein electrophoresis, genetic variability, wolf-dog interbreeding, wolf conservation, Italy

\section{Introduction}

In Italy the decline of the wolf Canis lupus Linnaeus, 1758 started last century (Cagnolaro et al. 1974, Boitani 1992). Both habitat fragmentation and direct extermination by shooting, trapping or poisoning were responsible for the considerable decrease of population size. Since the last wolf disappeared from the Alps at about one hundred years ago (Cagnolaro et al. 1974), the Italian population remained isolated from the other European wolf stocks. As a result of a systematic persecution supported and reinforced by the law, the wolf population presumably 
reached its lowest number after World War II (Ciucci and Boitani 1991). In 1973, an indirect census conducted by Zimen and Boitani (1975) yielded an estimate of about 100 wolves for a range of 8500 square kilometres throughout the Apennines. At that time, the Italian wolves were separated into two presumably isolated populations, one living in the south and the other in the central part of the country. In 1976 the wolf was considered a threatened species and fully protected throughout Italy. Conservation efforts, such as the legal protection, public education campaigns, and the introduction of natural prey, allowed the wolf to spread and to increase in population size and range. Recent estimates amount to about 300-400 wolves for a range of 17000 square kilometres (Boscagli 1991, Ciucci and Boitani 1991). The present distribution of wolf ranges from the extreme south to the north-western regions of Italy, throughout the mountaneous areas of the Apennines (Fig. 1). Recently, also the reappearance of wolves in the French Mercantour Park has been reported (Lequette et al. 1994).

In Italy, human activities still have a considerable impact on the wolf (Guberti and Francisci 1991, Francisci and Guberti 1993, R. Fico, in prep.). In spite of the opportunistic behaviour and the great dispersal capability of the species (Mech 1987), the consistent presence of man hampers the wolf in colonising new areas. Apart from these demographic problems, the genetic purity of the species may be threatened. Some authors consider the interbreeding with domestic dogs one of the major threats to the integrity of the gene pool of the Italian wolf (Boitani 1982, 1983, 1984, Boitani and Fabbri 1983, Ciucci and Boitani 1991). In some areas inhabited by wolves (especially central to southern Italy), roaming dogs are present in large numbers (Boitani and Fabbri 1983, Fico 1995). Cross-breeding with dogs may have helped the wolf to recover from the bottleneck in the $1970 \mathrm{~s}$, but at the same time may have contributed to a loss of the genetic integrity of the species (Ciucci and Boitani 1991, Boitani 1992).

The genetic structure of the Italian wolf population has been investigated only recently (Fusco et al. 1991, Randi 1993, Randi et al. 1993). Comparisons with the genetic variability of the dog have not been carried out so far. It is the aim of the present study to assess the level of genetic variability in the wolf population of central Italy in relation to recent demographic changes. Furthermore, by examining differences in allelic frequencies at loci polymorphic both in the wolf and the dog, the impact of interbreeding between both forms on the gene pool of the wolf will be evaluated.

\section{Material and methods}

Tissue samples of 46 wolves and 53 mongrel dogs from central Italy were collected by the Istituto Zooprofilattico Sperimentale, Teramo, over a period of 3 years. Carcasses of illegally killed or retrieved dead wolves were provided by the Forestry Service for post-mortem examinations. Wolves came mainly from Abruzzo (Fig. 1), which is still the region with the highest wolf density (Boitani and Fabbri 1983). Dogs were collected from the public kennel or directly from dog owners. To achieve a large array of dog 

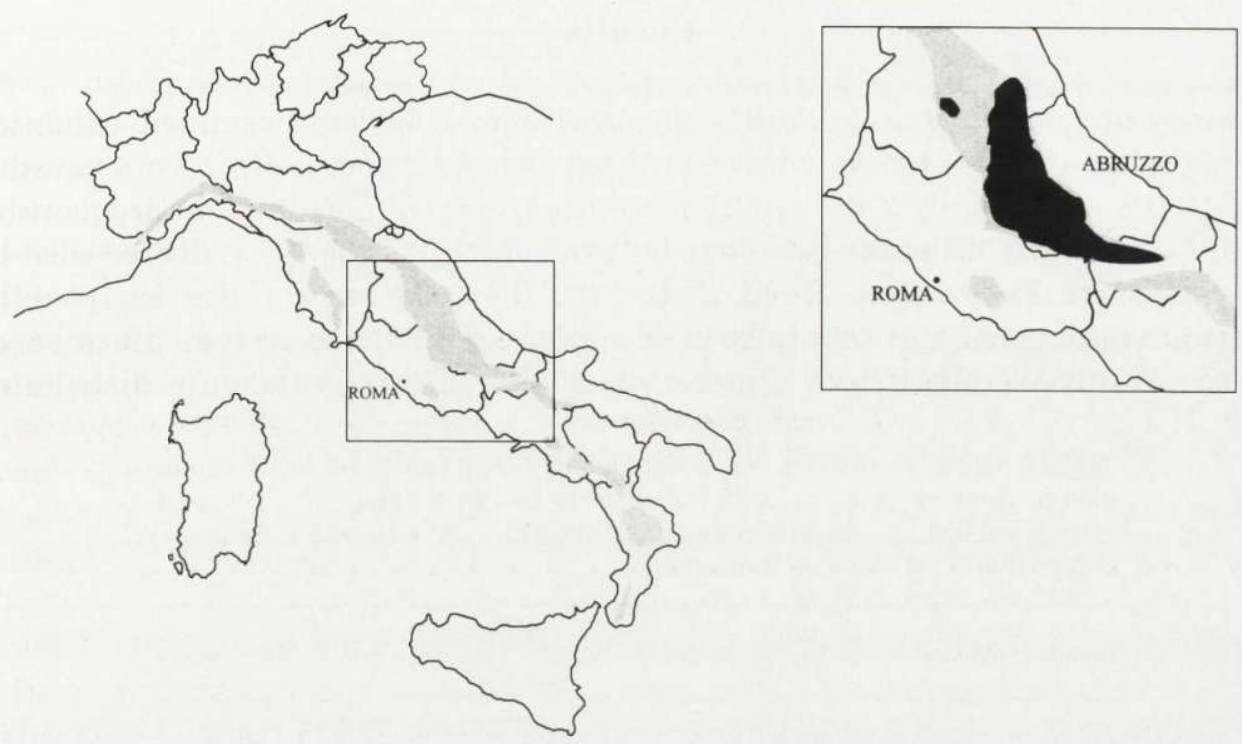

Fig. 1. Range (shaded) and sampling area (dark) of the wolf in Italy (range redrawn after Ciucci and Boitani 1991).

alleles, we sampled only unrelated mongrels. Preparation of liver and heart extracts, electrophoresis, and staining procedures followed standard laboratory techniques (Lorenzini et al. 1993) adapted from Shaw and Prasad (1970), Harris and Hopkinson (1976), and Murphy et al. (1990).

Twenty-eight enzyme and protein systems encoded by 41 presumptive gene loci were examined for polymorphism using vertical polyacrylamide gel electrophoresis. The following loci were scored (abbreviation and E.C.number are given in parentheses): acid phosphatase (Acp, 3.1.3.2), adenosine deaminase (Ada , 3.5.4.4), adenylate kinase (Ak-1, $A k-2,2.7 .4 .3)$, albumin (Alb), alkaline phosphatase (Alp , 3.1.3.1), aldolase (Aldo, 4.1.2.13), aspartate aminotransferase (Aat-1, Aat-2, 2.6.1.1), creatine kinase $(C k-1, C k-2,2.7 .3 .2)$, esterases (Est-1, Est-2, 3.1.1.1), fructose-1,6-diphosphatase ( $F d p$, 3.1.3.11), fumarate hydratase $(F h, 4.2 .1 .2)$, glucose dehydrogenase $(G d h, 1.1 .1 .47)$, glucosephosphate isomerase ( $\mathrm{Gpi}, 5.3 .1 .9)$, haemoglobin ( $\mathrm{Hb}-1, \mathrm{Hb}-2)$, isocitrate dehydrogenase (Idh-1, Idh-2,1.1.1.42), lactate dehydrogenase ( $L d h-1, L d h-2,1.1 .1 .27)$, malate dehydrogenase (Mor-1, Mor-2, 1.1.1.37), malic enzyme (Mod-1, Mod-2, 1.1.1.40), mannosephosphate isomerase (Mpi, 5.3.1.8), NADH-diaphorase (Dia-1, Dia-2, 1.6.2.2), non-enzymatic heart proteins (Pt-1, Pt-2, Pt-3), peptidases (Pep-A, Pep-B, 3.4.11), phosphoglucomutase $(P g m, 2.7 .5 .1), 6$-phosphogluconate dehydrogenase ( $P g d, 1.1 .1 .44)$, purine nucleoside phosphorylase $(N p, 2.4 .2 .1)$, superoxide dismutase (Sod-1, Sod-2, 1.15.1.1), xanthine dehydrogenase ( $X d h, 1.2 .3 .2)$.

Estimates of observed $\left(H_{o}\right)$ and expected $\left(H_{e}\right)$ average heterozygosity, and the proportion of polymorphic loci $(P, 99$ per cent criterion) were calculated according to Nei (1987). Genotypic proportions observed were examined for significant deviations from Hardy-Weinberg expectations using contingency $\chi^{2}$ goodness-of-fit analyses for each variable locus (Sokal and Rohlf 1981). The inbreeding coefficient $(F$, Wright 1951) was also computed. Relative genetic differentiation among samples was assessed using Wright's (1978) fixation index $\left(F_{S T}\right)$ for each variable locus. Statistical significance of $F_{S T}$ values was evaluated by $\chi^{2}$-tests (Workman and Niswander 1970). Estimates of genetic distance were calculated according to Nei (unbiased $D, 1978$ ), and to Cavalli-Sforza and Edwards (chord $D$, 1967). Statistical analyses were done using the BIOSYS-1 program (release 1.7) of Swofford and Selander (1989). 


\section{Results}

Six (Aat-1, Ada, Dia-1, Dia-2, Gpi, Mpi) out of 41 loci examined exhibited polymorphism in wolves. Only three of these loci (Ada, Dia-1, Mpi) were variable also in the dog sample (Table 1). At three loci (Ada, Gpi, Mpi) allelic frequencies were significantly different between the two samples, which is reflected also by the respective $F_{S T}$ values (Table 1 ). In both the wolf and the dog sample, the distribution of genotypes was fully in accordance with the expected values based on the Hardy-Weinberg law. Heterozygous wolves were randomly distributed

Table 1. Gene frequencies and Wright's (1978) $F_{S T}$ values for loci polymorphic in the wolf population of central Italy and in the dog $\left(^{* *}-p<0.01\right.$ *** $-\mathrm{p}<0.001, \mathrm{~ns}-$ statistically not significant). ${ }^{1}$ Alleles with a frequency of less than 0.01 are also indicated.

\begin{tabular}{lllll}
\hline Locus & Allele & $\begin{array}{c}\text { Wolf } \\
(n=46)\end{array}$ & $\begin{array}{c}\text { Dog } \\
(n=53)\end{array}$ & $F_{S T}$ \\
\hline Aat-1 & $a$ & 0.977 & 1.0 & \\
& $b$ & 0.023 & 0.0 & $0.011 \mathrm{~ns}$ \\
Ada & $a$ & 0.278 & 0.925 & $0.436^{* * * *}$ \\
& $b$ & 0.722 & 0.075 & \\
Dia-1 & $a$ & 0.314 & 0.193 & $0.019 \mathrm{~ns}$ \\
& $b$ & 0.686 & 0.807 & \\
Dia-2 & $a$ & 0.012 & 0.0 & \\
& $b$ & 0.988 & 1.0 & $0.006 \mathrm{~ns}$ \\
Gpi & $a$ & 0.0 & $0.009^{1}$ & \\
& $b$ & 0.922 & 0.991 & $0.005 \mathrm{~ns}$ \\
& $c$ & 0.078 & 0.0 & \\
Ldh-1 & $a$ & 1.0 & 0.991 & $0.045^{* *}$ \\
& $b$ & 0.0 & $0.009^{1}$ & \\
Mpi & $a$ & 0.564 & 0.764 & \\
& $b$ & 0.436 & 0.236 & \\
\hline
\end{tabular}

Table 2. Observed $\left(H_{o}\right)$ and expected $\left(H_{e}\right)$ average heterozygosity, proportion of polymorphic loci ( $P$, 99 per cent criterion), and average number of alleles per locus $(A)$ in the wolf population of central Italy and in the dog. All values are calculated over 41 presumptive loci.

\begin{tabular}{lll}
\hline & Wolf & \multicolumn{1}{c}{ Dog } \\
\hline$H_{o}$ & 0.036 & 0.019 \\
$\mathrm{H}_{e}$ & 0.037 & 0.020 \\
$P$ & 0.146 & 0.073 \\
$A$ & 1.1 & 1.1 \\
\hline
\end{tabular}

throughout the entire sampling area. A slight, but statistically insignificant heterozygote deficiency in the wolf was suggested by positive $F_{I S}$-values at $G p i$ and $A d a$. The proportion of polymorphic loci in the wolf $(P=0.146)$ was twice as high as that in the $\operatorname{dog}(P=0.073)$. Approximately the same holds for expected average heterozygosity (wolf: $H_{e}=0.037$, dog: $\left.H_{e}=0.020\right)$. The average number of alleles per locus was $A=1.1$ in both samples (Table 2). Mean $F_{S T}$ was 0.167 
$(p<0.01)$. Nei's (1978) genetic distance between the wolf and the dog was 0.012 , Cavalli-Sforza and Edwards' (1967) chord distance was 0.084 .

\section{Discussion}

Genetic variability was very low in the $\operatorname{dog}\left(P=0.073, H_{e}=0.020\right)$ as compared to its wild counterpart, which showed higher values of both the proportion of polymorphic loci and average heterozygosity $\left(P=0.146, H_{e}=0.037\right)$. These findings are in accordance with low levels of protein variation already reported in previous studies (Simonsen 1976, Weiden et al. 1974), but are inconsistent with the wide range of morphological variation generally observed in the domestic dog. Low protein variation found in previous studies may be explained by the investigation of only a small number of loci or of using only highly inbred dogs, but clearly these arguments do not hold for the present case.

The low protein variability found even in mongrels suggests that a great deal of polymorphism was lost as a consequence of domestication (Lawrence 1967, Davis and Valla 1978, Olsen 1985). First, undoubtedly only a limited part of the genetic diversity present in the wolf was included in the ancestral founder population of domestic dog (Clutton-Brock 1984). Second, strong disruptive selection for particular expressions of morphological or behavioural traits, the relaxation of natural selection, and recombination may have led to an increase of phenotypic variation. By contrast, selectively neutral alleles (at least with respect to breeding targets) at protein loci may have been increasingly lost due to repeated bottlenecking associated with domestication and the establishment of new races. Given the short time of domestication the impact of new mutations on variability at the few dozen of protein loci studied can certainly be neglected.

As reported previously (Fisher et al. 1976, Simonsen 1976, Ferrel et al. 1980, Juneja et al. 1981, Braend and Røed 1987), there were no fixed allelic differences between wolf and dog. The biggest allelic difference was found at Ada, where the frequency of the allele ' $b$ ' was one order of magnitude lower in the dog than in the wolf. At Gpi, three alleles were found: ' $b$ ', the most common one in both forms, 'c' being present exclusively in the wolf, and ' $a$ ' being present at a very low frequency (only one heterozygote observed) exclusively in the dog. However, while the ' $a$ '-allele was detected at a low frequency also in the Italian wolf population (Randi et al. 1993), the 'c'-allele is known to be present also in the dog (Tanabe 1977, Richkind and Richkind 1978, Ferrel et al. 1980).

Our estimate of Nei's (1978) genetic distance between wolf and $\operatorname{dog}(D=0.012)$ is very similar to $D=0.013$ obtained by Wayne and O'Brien (1987), and slightly higher than the distance between the gray wolf and the dingo $(D=0.008)$ obtained by Fisher et al. (1976). Cavalli-Sforza and Edwards' chord distance of 0.084 is comparable with that of Fisher et al. (1976) (chord $D=0.095$ ), and rather high as compared to chord $D=0.050$ obtained by Wayne and O'Brien (1987). Our FST of 0.167 was slightly higher than a range of $0.003-0.137$ obtained by Jordana et al. 
Table 3. Values of absolute ( $D$, Nei 1978; chord $D$, Cavalli-Sforza and Edwards 1967) and relative $\left(F_{S T}\right.$, Wright 1978) genetic differentiation between wolf and dog, wolf and dingo, and among dog breeds. $n$ - number of loci. ${ }^{* * *}-\mathrm{p}<0.001, \mathrm{nc}-$ not computed.

\begin{tabular}{llllll}
\hline & $n$ & $D$ & Chord $D$ & \multicolumn{1}{c}{$F_{S T}$} & \multicolumn{1}{c}{ Reference } \\
\hline Wolf/dingo & 53 & 0.008 & 0.095 & 0.401 & Fisher et al. 1976 \\
Dog/dog & 21 & $\mathrm{nc}$ & $\mathrm{nc}$ & $\begin{array}{l}0.099 \\
\text { Jordana } \text { et al. 1992 }\end{array}$ \\
Wolf/dog & 44 & 0.013 & 0.050 & $\begin{array}{l}0.003-0.137) \\
\text { nc }\end{array}$ & $\begin{array}{l}\text { Wayne and O'Brien 1987 } \\
\text { Wolf/dog }\end{array}$ \\
\hline
\end{tabular}

(1992) in pairwise comparisons of ten Spanish dog breeds (Table 3). Altogether, these results confirm that wolf and dog are very closely related forms.

In the Italian wolf, estimates of polymorphism and heterozygosity $\left(P=0.146, H_{e}\right.$ $=0.037)$ are intermediate as compared to the range of values reported for natural populations of wolf-like canids (Fisher et al. 1976, Wayne et al. 1991, Kennedy et al. 1991), but are similar to recently published data on some gray wolf populations (Table 4). $P$ - and $H$-values in the present study are higher than those obtained previously for the Italian wolf population (Randi et al. 1993), which is due to the identification of $A d a$ as an additional highly variable locus. Generally, taking into account the serious population bottleneck the Italian wolf experienced after World War II, levels of genetic variability are high, both in terms of a comparatively large number of highly variable loci and in terms of the presence of several rare alleles. Especially the latter is surprising, as the number of rare alleles is known to be considerably more affected by genetic bottlenecks than average heterozygosity (Frankel and Soulé 1981, Leberg 1990, Amos and Hoelzel 1992, Hartl and Pucek 1994). How can our findings be explained? First, due to a rapid recovery of the wolf population during the last 20 years, the bottleneck lasted only for a few generations. Second, due to technical difficulties, the remaining number of wolves may have been underestimated in the first census in 1973 (cf Cagnolaro et al. 1974, Francisci and Guberti 1993). Recent evidence of monomorphism in mitochondrial DNA seems to be better explained by a long period of isolation from the other European populations rather than by a severe population bottleneck (Randi et al. 1993).

Table 4. Estimates of genetic variability in some gray wolf populations. $n$ - number of loci, $P-$ percentage of polymorphic loci, $H_{o}\left(H_{e}\right)$ - observed (expected) average heterozygosity.

\begin{tabular}{rccccl}
\hline Sample size & $n$ & $P$ & $H_{o}$ & $H_{e}$ & \multicolumn{1}{c}{ Reference } \\
\hline \multicolumn{1}{r}{188} & 37 & 0.135 & 0.030 & 0.030 & Kennedy et al. 1991 (Canada) \\
12 & 53 & 0.113 & 0.028 & 0.038 & Fisher et al. 1976 (Zoo) \\
33 & 25 & 0.200 & 0.061 & 0.087 & Wayne et al. 1991 (Minnesota) \\
7 & 25 & 0.080 & 0.040 & 0.039 & Wayne et al. 1991 (Isle Royal) \\
32 & 40 & 0.100 & 0.028 & 0.029 & Randi et al. 1993 (Italy) \\
46 & 41 & 0.146 & 0.036 & 0.037 & this study (Italy) \\
\hline
\end{tabular}


Cross-breeding with domestic dog is still considered one of the major threats to the survival of genetically pure wolves by some authors (eg Boitani 1982,1984). The patterns of genetic variability and differentiation obtained in the present study do not suggest substantial interbreeding between wolf and dog. Only little genetic exchange per generation would have sufficed to make allelic frequencies at loci polymorphic in both forms much more similar than they actually are (Table 1). Results from restriction fragment analyses of mitochondrial DNA did not suggest introgression of maternally inherited dog genes into the gene pool of the Italian wolf (Randi et al. 1993). Field observations also indicate that mates between female dogs and male wolves are not common. They have never been documented for the Italian population. Crosses between male dogs and female wolves are thought to be more common (Zimen 1978, Mendelssohn 1982, Boitani 1984). Genetic contributions of male domestic dogs could be proved by assessing variation at hypervariable nuclear genes, but no such data are available so far.

In the light of both population genetic and demographic evidence, we suggest that the following points be considered in management of the Italian wolf:

1. The preservation of suitable habitats and especially the prevention of further habitat fragmentation (as far as the coexistence with man can permit) should be the best strategy for conservation of the wolf population. The presence of continuous wooded areas allows wolves to spread and to colonize new territories. Natural or artificial corridors among suitable habitat patches should facilitate the dispersion of young animals and, thus, lead to an increase of newly formed packs.

2. In order to avoid illegal killings in areas like central Italy, where wolf attacks to livestock are numerous, regional governments should be more efficient in verifying wolf-caused damages and providing compensation to the farmers. In particular, for the Abruzzo and the Tuscany region, the coexistence between the predator and domestic animals is going to become a problem because of the growing number of wolves (R. Fico, in prep.).

3. According to the present genetic data, the occurrence of interbreeding with dog does not seem to have threatened the genetic identity of the Italian wolf. The potential benefits gained from establishing a captive population of pure, unrelated, and non-inbred wolves, as advocated by Ciucci and Boitani (1991), are outweighed by all the genetic problems usually associated with captive populations (founder effect, random drift) together with the necessity of simulating gene flow and avoiding inbreeding by a repeated introduction of animals from the wild.

4. The promotion of a positive image of the wolf, already begun some years ago, is still very important and should be continued. The popularization of scientific achievements and the continuous information of the public through the media are some of the best ways to implement an effective conservation of wolves in Italy.

Acknowledgements: We are grateful to S. Lovari for reviewing an earlier version of this manuscript. The cooperation of the Forestry Service (Corpo Forestale dello Stato) and the graphic support of S. Santarelli are also appreciated. 


\section{References}

Amos B. and Hoelzel A. R. 1992. Applications of molecular genetic techniques to the conservation of small populations. Biological Conservation 61: 133-144.

Boitani L. 1982. Wolf management in intensively used areas of Italy. [In: Wolves of the world. F. H. Herrington and P. C. Paquet, eds]. Noyes Publications, New Jersey: 158-172.

Boitani L. 1983. Wolf and dog competition in Italy. Acta Zoologica Fennica 174: 259-264.

Boitani L. 1984. Genetic considerations on wolf conservation in Italy. Bollettino di Zoologica 51: 367-373.

Boitani L. 1992. Wolf research and conservation in Italy. Biological Conservation 61: 125-132.

Boitani L. and Fabbri M. L. 1983. National strategy for wolf (Canis lupus). Ricerche di Biologia della Selvaggina 72: 1-30. [In Italian with English summary]

Boscagli G. 1991. Evolution of captive-bred wolves (Canis lupus italicus) in the Abruzzo National Park, and situation of the wolf population in Italy. Situation of the brown bear (Ursus arctos marsicanus) from central Apennine. [In: Genetics and wildlife conservation. E. Randi and M. Spagnesi, eds]. Supplemento alle Ricerche di Biologia della Selvaggina 18: 219-225. [In Italian with English summary]

Braend M. and Røed K. H. 1987. Polymorphism of transferrin and esterase in Alaskan wolves. Evidence of close molecular homology with the dog. Animal Genetics 18: 143-148.

Cagnolaro L., Rosso D., Spagnesi M. and Venturi B. 1974. Investigation on the distribution of the wolf (Canis lupus) in Italy and in the Ticino and Grigioni cantons (Switzerland). Ricerche di Biologia della Selvaggina 59: 1-75. [In Italian with English summary]

Cavalli-Sforza L. L. and Edwards A. W. F. 1967. Phylogenetic analysis: models and estimation procedures. Evolution 21: 550-570.

Ciucci P. and Boitani L. 1991. Viability assessment of the Italian wolf and guidelines for the management of the wild and a captive population. Ricerche di Biologia della Selvaggina 89: 1-58. [In Italian with English summary]

Clutton-Brock J. 1984. Dog. [In: Evolution of domesticated animals. I. L. Mason, ed]. Longman, London: 198-211.

Davis S. and Valla F. R. 1978. Evidence for the domestication of the dog 12000 years ago in the Natufian of Israel. Nature 276: 608-610.

Ferrel R. E., Morizot D. C., Horn J. and Carley C. J. 1980. Biochemical markers in a species endangered by introgression: the red wolf. Biochemical Genetics 18: 39-49.

Fico R. 1995. Study and management of a dog population. ISS/WHO/FAO-CC/IZS-TE 95-25: 1-60.

Fisher R. A., Putt W. and Hackel E. 1976. An investigation of the products of 53 gene loci in three species of wild Canidae: Canis lupus, Canis latrans, and Canis familiaris. Biochemical Genetics 14: $963-974$.

Francisci F. and Guberti V. 1993. Recent trends of wolves in Italy as apparent from kill figures and specimens. [In: Wolves in Europe. Status and perspectives. C. Promberger and W. Schröeder, eds]. Wildbiologische Gesellschaft München: 91-102.

Frankel O. H. and Soulé M. E. (eds) 1981. Conservation and evolution. Cambridge University Press, Cambridge: 1-327.

Fusco G., Lorenzini R., Lucchini V., Francisci F. and Randi E. 1991. Genetic variability, examined by electrophoresis, in a sample of wolves (Canis lupus) from Italy. [In: Genetics and wildlife conservation. E. Randi and M. Spagnesi, eds]. Supplemento alle Ricerche di Biologia della Selvaggina 18: 175-183. [In Italian with English summary]

Guberti V. and Francisci F. 1991. Causes of death in 60 wolves collected in Italy since 1984. IIn: Atti del II Convegno Nazionale dei Biologi della Selvaggina. M. Spagnesi and S. Toso, eds]. Supplemento alle Ricerche di Biologia della Selvaggina 19: 599-603. [In Italian with English summary] 
Harris H. and Hopkinson D. A. 1976. Handbook of enzyme electrophoresis in human genetics. North Holland Publ. Co., Amsterdam.

Hartl G. B. and Pucek Z. 1994. Genetic depletion in the European bison (Bison bonasus) and the significance of electrophoretic heterozygosity for conservation. Conservation Biology 8: 167-174.

Jordana J., Piedrafita J., Sanchez A. and Puig P. 1992. Comparative F statistics analysis of ten Spanish dog breeds. Journal of Heredity 83: 367-374.

Juneja R. K., Reetz I., Christensen K., Gahne B. and Andresen E. 1981. Two-dimensional gel electrophoresis of dog plasma proteins: genetic polymorphism of an $\alpha_{1}$-protease inhibitor and another postalbumin. Hereditas 95: 225-233.

Kennedy P. K., Kennedy M. L., Clarkson P. L. and Liepins I. S. 1991. Genetic variability in natural populations of the gray wolf, Canis lupus. Canadian Journal of Zoology 69: 1183-1188.

Lawrence B. 1967. Early domestic dog. Zeitschrift für Säugetierkunde 32: 44-59.

Leberg P. L. 1990. Genetic considerations in the design of introduction programs. Transactions of the 55th North American Wildlife and Natural Resources Conference: 609-619.

Lequette B., Houard T., Del Corso L., Mari F. and Boscagli G. 1994. [Wolf comes back to the Maritime Alps: Preliminary data]. I Congresso Italiano di Teriologia, Pisa 27-28 October 1994, Riassunti: 87. [In Italian]

Lorenzini R., Patalano M., Apollonio M. and Mazzarone V. 1993. Genetic variability of roe deer Capreolus capreolus in Italy: electrophoretic survey on populations of different origin. [In: Ecological genetics in mammals. G. B. Hartl and J. Markowski, eds]. Acta Theriologica 38, Suppl. 2: $141-151$.

Mech L. D. 1987. Age, season, distance, direction and social aspects of wolf dispersal from a Minnesota pack. [In: Mammalian dispersal patterns. B. D. Chepko-Sade and Z. T. Halpin, eds]. University of Chicago Press, Chicago, Illinois: 55-74.

Mendelssohn H. 1982. Wolves in Israel. [In: Wolves of the world. F. H. Herrington and P. C. Paquet, eds]. Noyes Publications, New Jersey: 173-195.

Murphy R. W., Sites J. W., Donald G. B. and Haufler C. H. 1990. Protein I: isozyme electrophoresis. [In: Molecular systematics. D. M. Hillis and C. Moritz, eds]. Sinauer Associates, Sunderland, Massachusetts: $45-126$.

Nei M. 1978. Estimation of average heterozygosity and genetic distance from a small number of individuals. Genetics 89: 583-590.

Nei M. 1987. Molecular evolutionary genetics. Columbia University Press, New York: 1-512.

Olsen S. J. 1985. Origins of the domestic dog. The fossil records. University of Arizona Press, Tuscon: $1-239$.

Randi E. 1993. Effects of fragmentation and isolation on genetic variability of the Italian populations of wolf Canis lupus and brown bear Ursus arctos. [In: Ecological genetics in mammals. G. B. Hartl and J. Markowski, eds]. Acta Theriologica 38, Suppl. 2: 113-120.

Randi E., Lucchini V. and Francisci F. 1993. Allozyme variability in the Italian wolf (Canis lupus) population. Heredity 71: 516-522.

Richkind K. E. and Richkind M. 1978. Polymorphism of the glucose phosphate isomerase locus in the dog. Journal of Heredity 69: 141-142.

Shaw C. R. and Prasad R. 1970. Starch gel electrophoresis of enzymes. A compilation of recipes. Biochemical Genetics 4: 297-320.

Simonsen V. 1976. Electrophoretic studies on the blood proteins of domestic dogs and other Canidae. Hereditas 82: 7-18.

Sokal R. R. and Rohlf F. J. 1981. Biometry. W. H. Freeman, San Francisco: 1-859.

Swofford D. L. and Selander R. K. 1989. BIOSYS-1. A computer program for the analysis of allelic variation in population genetics and biochemical systematics. Release 1.7, Illinois Natural History Survey, Champaign, Illinois.

Tanabe Y., Omi T. and Ota K. 1977. Genetic variants of glucose phosphate isomerase (EC 5.3.1.9) in canine erythrocytes. Animal Blood Groups and Biochical Genetics 8: 191-195. 
Wayne R. K., Lehman N., Girman D., Gogan P. J. P., Gilbert D. A., Hansen K., Peterson R. O., Seal U. S., Eisenhawer A., Mech L. D. and Krumenaker R. J. 1991. Conservation genetics of the endangered Isle Royal gray wolf. Conservation Biology 5: 41-51.

Wayne R. K. and O'Brien S. J. 1987. Allozyme divergence within the Canidae. Systematic Zoology 36: 339-355.

Weiden P., Storb R., Kolb H. J., Graham T., Anderson J. and Giblett E. 1974. Genetic variation of red blood cell enzymes in the dog. Transplantation 17 (1): 115-120.

Workman P. L. and Niswander J. D. 1970. Population studies on southwestern Indian tribes. II. Local genetic differentiation in the Papago. American Journal of Human Genetics 22: 24-49.

Wright S. 1951. The genetical structure of populations. Annals of Eugenics 15: 323-354.

Wright S. 1978. Evolution and the genetics of populations, Vol. 4. Variability within and among natural populations. University of Chicago Press, Chicago: 1-580.

Zimen E. 1978. Der Wolf. Mythos und Verhalten. Meyster Verlag, Wien: 1-270.

Zimen E. and Boitani L. 1975. Number and distribution of wolves in Italy. Zeitschrift für Säugetierkunde 40: 102-112.

Received 3 July 1995, accepted 30 August 1995. 